\title{
Association of polymorphisms at the ADIPOR1 regulatory region with type 2 diabetes and body mass index in a Brazilian population with European or African ancestry
}

\author{
E. Yeh ${ }^{1}$, L. Kimura ${ }^{1}$, F.I.V. Errera ${ }^{1,2}$, C.B. Angeli ${ }^{1}$, R.C. Mingroni-Netto ${ }^{1}$, M.E.R. Silva ${ }^{3}$, \\ L.H.S. Canani ${ }^{4}$ and M.R. Passos-Bueno ${ }^{1}$
}

${ }^{1}$ Centro de Estudos do Genoma Humano, Departamento de Genética e Biologia Evolutiva, Instituto de Biociências, Universidade de São Paulo, São Paulo, SP, Brasil

2Departamento de Morfologia, Escola Superior de Ciências, Santa Casa de Misericórdia de Vitória, Vitória, ES, Brasil

${ }^{3}$ Laboratório de Investigação Médica LIM-18, Hospital das Clínicas, Faculdade de Medicina, Universidade de São Paulo, São Paulo, SP, Brasil

${ }^{4}$ Divisão de Endocrinologia, Hospital das Clínicas de Porto Alegre, Universidade Federal do Rio Grande do Sul, Porto Alegre, RS, Brasil

Correspondence to: M.R. Passos-Bueno, Departamento de Genética e Biologia Evolutiva, Instituto de Biociências, USP, Rua do Matão, 277, 05508-900 São Paulo, SP, Brasil

E-mail: passos@ib.usp.br

\begin{abstract}
Association studies between ADIPOR1 genetic variants and predisposition to type 2 diabetes (DM2) have provided contradictory results. We determined if two single nucleotide polymorphisms (SNP c.-8503G>A and SNP c. 10225C >G) in regulatory regions of $A D I P O R 1$ in 567 Brazilian individuals of European (EA; $N=443$ ) or African (AfA; $N=124$ ) ancestry from rural (quilombo remnants; $N=439)$ and urban $(N=567)$ areas. We detected a significant effect of ethnicity on the distribution of the allelic frequencies of both SNPs in these populations $(E A:-8503 A=0.27$; AfA: $-8503 A=0.16 ; P=0.001$ and $E A$ : 10225G =0.35; AfA: $10225 G=0.51 ; P<0.001$ ). Neither of the polymorphisms were associated with DM2 in the case-control study in EA (SNP C.-8503G>A: DM2 group -8503A = 0.26; control group -8503A = 0.30; $P=0.14 /$ SNP 10225C >G: DM2 group 10225G = 0.37; control group $10225 G=0.32 ; P=0.40)$ and AfA populations (SNP c.-8503G>A: DM2 group -8503A = 0.16; control group -8503A $=0.15 ; P=0.34 /$ SNP $10225 C>G$ : DM2 group $10225 G=0.51$; control group $10225 G=0.52 ; P=0.50$ ). Similarly, none of the polymorphisms were associated with metabolic/anthropometric risk factors for DM2 in any of the three populations, except for $\mathrm{HDL}$ cholesterol, which was significantly higher in AfA heterozygotes (GC $=53.75 \pm 17.26 \mathrm{mg} / \mathrm{dL}$ ) than in homozygotes. We conclude that ADIPOR1 polymorphisms are unlikely to be major risk factors for DM2 or for metabolic/anthropometric measurements that represent risk factors for DM2 in populations of European and African ancestries.
\end{abstract}

Key words: Association study; Adiponectin receptors; Type 2 diabetes; Polymorphism for ancestry-admixture mapping; HDL cholesterol; Association of ADIPOR1 with DM2

Research supported by FAPESP (\#04/0185-5), CEPID (Centro de Excelência em Pesquisa, Inovação e Difusão, \#98/14254-2), and Hospital de Clínicas de Porto Alegre.

Received October 11, 2007. Accepted May 21, 2008 
Adiponectin is a circulating peptide secreted from adipose tissue that acts as an antidiabetic adipokine (1). In 2003, two adiponectin receptors encoding genes were described: adiponectin receptor 1 (ADIPOR1) and 2 (ADIPOR2) (2). Several case-control studies on single nucleotide polymorphisms (SNPs) in the ADIPOR1 gene and type 2 diabetes mellitus (DM2) have been conducted in different populations but with contradictory results. Although association has been found between polymorphisms at ADIPOR1 and DM2 in the Amish (3), all other studies have been negative, including American (4), Japanese (5), French (6), and UK populations (7). Interestingly, associations between ADIPOR1 SNPs and liver fat content or insulin sensitivity (8), and with anthropometric measurements, such as height, weight, body mass index (BMI) (9), have been suggested.

In order to determine the association of ADIPOR1 with susceptibility to DM2 and with anthropometric measurements, we investigated if variants in regulatory regions of ADIPOR1 (SNPs c.-8503G >A [rs6666089] in the promoter and c. $10225 C>G$ [rs7539542] in the 3' UTR region) are associated with DM2 or with anthropometric measurements and also with metabolic traits in DM2 Brazilian patients with European (EA) and African (AfA) ancestries from both rural (quilombo remnants) and urban areas. We also evaluated if the frequency of these SNPs differs between individuals of EA and AfA.

The total sample consisted of 567 individuals: 313 from a cohort being followed at the Federal University of Rio Grande do Sul (UFRGS) (10) and 254 at the Hospital das Clínicas of the Universidade de São Paulo (HC-USP). Among them, 443 were EA (Portuguese, Spanish, Italian, and German) descendants and 124 AfA (West Africa, Angola, Mozambique) descendents $(11,12)$. Patients were evaluated using a questionnaire, physical examination and laboratory tests. Diagnosis of DM2 was based on the guidelines from the Expert Committee report (13). Weight and height were measured without shoes and in lightweight clothes; BMI was classified according to the World Health Organization criteria (14). It was not possible to obtain data for these parameters for all patients. The reference group (control) consisted of 190 healthy DM2free blood donor volunteers at HC-USP (96 EA and 94 AfA, age: $48.28 \pm 16.39$ years), who were previously described by Errera et al. $(11,12)$. The main clinical and laboratory data are reported in Table 1 and were obtained as recommended previously $(11,12)$. A group of 439 non-diabetic quilombo remnant individuals was also included. Previous to the abolition of slavery in Brazil, many fugitive African slaves founded communities called "Quilombos". Currently, population groups living in Quilombos are referred as quilombo remnants, who are partially genetically isolated (15). Data on systolic blood pressure, diastolic blood pressure, height, weight, BMI, waist circumference, and plasma glucose level were available for the quilombo remnant individuals (15).

The Ethics Committees of the Instituto de BiociênciasUSP, of HC-USP, and of UFRGS approved the study. All subjects gave written informed consent.

Genomic DNA was extracted from peripheral blood using standard protocols and amplified PCR. Both SNPs were detected using SnuPE method (c.-8503G>A: 5' AAATAGTATTATTTTATTCC 3 ' and c. $10225 \mathrm{C}>$ G: 5 ' GAAA TCTTTGAATGCCAAGT) and a Megabace DNA sequencer

Table 1. Clinical characteristics of type 2 diabetes mellitus patients of European ancestry and African ancestry, and of non-diabetic individuals from quilombo remnant populations.

\begin{tabular}{|c|c|c|c|c|c|c|}
\hline & \multicolumn{2}{|c|}{ European ancestry } & \multicolumn{2}{|c|}{ African ancestry } & \multicolumn{2}{|c|}{ Quilombo remnants } \\
\hline & Mean \pm SD & $\mathrm{N}$ & Mean \pm SD & $\mathrm{N}$ & Mean \pm SD & $\mathrm{N}$ \\
\hline Age (years) & $52.72 \pm 15.08$ & 443 & $50.22 \pm 14.74$ & 124 & $43.42 \pm 17.57$ & 439 \\
\hline Systolic blood pressure $(\mathrm{mmHg})$ & $142.2 \pm 23.4$ & 331 & $141.28 \pm 24.1$ & 51 & $127.32 \pm 24.3$ & 439 \\
\hline Diastolic blood pressure $(\mathrm{mmHg})$ & $85.67 \pm 12.8$ & 331 & $86.11 \pm 12.3$ & 51 & $82.92 \pm 13.4$ & 439 \\
\hline Body mass index $\left(\mathrm{kg} / \mathrm{m}^{2}\right)$ & $28.5 \pm 5.3$ & 387 & $28.7 \pm 5.4$ & 105 & $24.8 \pm 4.4$ & 439 \\
\hline Waist circumference $(\mathrm{cm})$ & $98.0 \pm 11.9$ & 132 & $98.4 \pm 12.6$ & 26 & $83.2 \pm 10.6$ & 438 \\
\hline Total cholesterol (mg/dL) & $210 \pm 47.2$ & 437 & $209 \pm 78.2$ & 105 & NA & \\
\hline HDL cholesterol (mg/dL) & $44.8 \pm 12.9$ & 437 & $49.6 \pm 14.3$ & 105 & NA & \\
\hline LDL cholesterol (mg/dL) & $133.8 \pm 43.5$ & 437 & $133.9 \pm 47.5$ & 105 & NA & \\
\hline Serum creatinine $(\mathrm{mg} / \mathrm{dL})$ & $1.31 \pm 1.39$ & 380 & $1.87 \pm 2.57$ & 94 & NA & \\
\hline Triglycerides (mg/dL) & $186.8 \pm 146.7$ & 437 & $142.2 \pm 103.9$ & 101 & NA & \\
\hline $\mathrm{HbA} 1 \mathrm{C}(\%)$ & $8.39 \pm 2.6$ & 304 & $9.22 \pm 2.9$ & 86 & NA & \\
\hline Fasting plasma glucose (mg/dL) & $176.4 \pm 71.3$ & 354 & $172.0 \pm 67.9$ & 94 & $97.63 \pm 31.9$ & 438 \\
\hline
\end{tabular}

$\mathrm{N}=$ number of individuals for whom information was available. $\mathrm{NA}=$ data not available. 
(SNuPe, Amersham, Piscataway, NJ, USA).

Association studies were performed between a set of 315 DM2 patients (246 EA and 69 AfA) and the control group, both within a comparable age range (mean age DM2 patients: $52.39 \pm 16.34$ years; mean age control group: $48.28 \pm 16.39$ years). Distribution of genotypes and alleles was compared using the $\chi^{2}$ or the Fisher exact test. The level of significance adopted was $P<0.05$. Statistical analyses were carried out with SSPS (Statistical Package for the Social Sciences for Windows, version 10.0). Sample size power was calculated with PS Power and Sample Size Calculations, version 2.1.30 (16).

Genotypic distributions for the SNPs c.-8503G>A and c. $10225 \mathrm{C}>\mathrm{G}$ were in Hardy-Weinberg equilibrium in all groups $(P>0.05)$.

Ethnicity had a significant effect on the distribution of the allelic frequencies of these two SNPs in the DM2 and control groups, in which the $G$ allele of both SNPs was more frequent in AfA than in EA (EA: -8503A = 0.27, AfA: $-8503 A=0.16, P=0.001 ; E A: 10225 G=0.35 ;$ AfA: $10225 \mathrm{G}=0.53, \mathrm{P}<0.001 ;$ Table 2).

There were no significant differences in genotypic and allelic frequencies of SNPs -8503 and c. 10225 between DM2 patients and the control population: [EA (SNP C.-8503G>A: DM2 group -8503A = 0.26; control group $-8503 A=0.30 ; P=0.14 ;$ SNP $10225 C>G$ : DM2 group
$10225 \mathrm{G}=0.37$; control group $10225 \mathrm{G}=0.32 ; \mathrm{P}=0.40)]$ or [AfA (SNP c.-8503G>A: DM2 group -8503A = 0.16; control group $-8503 A=0.15 ; P=0.34 ; S N P 10225 C>G$ : DM2 group $10225 \mathrm{G}=0.51$; control group $10225 \mathrm{G}=0.52 ; \mathrm{P}=$ $0.50)$ ], suggesting that these SNPs are not associated with DM2 in these groups.

The effect of the genotypes on quantitative laboratory data and anthropometric features of DM2 patients was compared by the unpaired Student $t$-test and ANOVA. These parameters were not associated with any genotype of the SNP c.-8503G>A/ADIPOR1 [total cholesterol (EA: $P$ $=0.69 ;$ AfA: $P=0.50)$, HDL cholesterol (EA: $P=0.23 ;$ AfA: $P=0.26)$, LDL cholesterol (EA: $P=0.85$; AfA: $P=0.43)$, serum creatinine $(E A: P=0.13 ; A f A: P=0.89)$, triglycerides (EA: $P=0.31$; AfA: $P=0.31)$, systolic blood pressure (EA: $P=0.83$; AfA: $P=0.29)$, diastolic blood pressure (EA: $P=$ 0.55; AfA: $P=0.95), H b A 1 c(E A: P=0.16 ;$ AfA: $P=0.97)$, plasma glucose (EA: $P=0.10 ; A f A: P=0.28)$, height $(E A$ : $P=0.36 ;$ AfA: $P=0.90)$, weight $(E A: P=0.79$; AfA: $P=$ $0.15)$, BMI (EA: $P=0.92 ; A f A: P=0.18$ ), and waist circumference (EA: $P=0.68 ;$ AfA: $P=0.91)$ ].

In contrast, analysis of SNP $10225 \mathrm{C}>\mathrm{G}$ in 156 DM2 patients with BMI information showed an association between the $10225 \mathrm{G}$ allele in EA and low BMI with borderline level of significance $(P=0.037)$, but not with any other parameter (data not shown). We genotyped an additional

Table 2. Genotypic frequencies of two ADIPOR1 gene single nucleotide polymorphisms (SNP) in the studied populations and $\mathrm{P}$ value for different pairs of population comparisons.

\begin{tabular}{|c|c|c|c|c|c|c|c|c|c|c|c|}
\hline \multirow[t]{3}{*}{ SNP } & \multicolumn{3}{|c|}{ EA } & \multicolumn{3}{|c|}{ AfA } & \multirow{3}{*}{$\begin{array}{l}\text { Quilombo } \\
\text { remnants }\end{array}$} & \multicolumn{4}{|c|}{$\mathrm{P}$ value } \\
\hline & \multirow[t]{2}{*}{ DM2 } & \multirow[t]{2}{*}{ Control } & \multirow[t]{2}{*}{ Total } & \multirow[t]{2}{*}{ DM2 } & \multirow[t]{2}{*}{ Control } & \multirow[t]{2}{*}{ Total } & & \multirow[t]{2}{*}{ EA vs AfA } & \multicolumn{2}{|c|}{ Control vs DM2 } & \multirow{2}{*}{$\begin{array}{l}\text { AfA vs } \\
\text { Quilombo } \\
\text { remmants }\end{array}$} \\
\hline & & & & & & & & & In EA & In AfA & \\
\hline c. $-8503 G>A$ & & & & & & & & 0.001 & 0.14 & 0.34 & - \\
\hline GG & $\begin{array}{c}135 \\
(54.9 \%)\end{array}$ & $\begin{array}{c}49 \\
(51 \%)\end{array}$ & $\begin{array}{c}184 \\
(53.8 \%)\end{array}$ & $\begin{array}{c}47 \\
(68.1 \%)\end{array}$ & $\begin{array}{c}56 \\
(71.8 \%)\end{array}$ & $\begin{array}{c}103 \\
(70.1 \%)\end{array}$ & - & & & & \\
\hline$A G$ & $\begin{array}{c}95 \\
(38.6 \%)\end{array}$ & $\begin{array}{c}36 \\
(37.5 \%)\end{array}$ & $\begin{array}{c}131 \\
(38.3 \%)\end{array}$ & $\begin{array}{c}22 \\
(31.9 \%)\end{array}$ & $\begin{array}{c}20 \\
(25.6 \%)\end{array}$ & $\begin{array}{c}42 \\
(28.6 \%)\end{array}$ & - & & & & \\
\hline$A A$ & $\begin{array}{c}16 \\
(6.5 \%)\end{array}$ & $\begin{array}{c}11 \\
(11.5 \%)\end{array}$ & $\begin{array}{c}27 \\
(7.9 \%)\end{array}$ & $\begin{array}{c}0 \\
(0 \%)\end{array}$ & $\begin{array}{c}2 \\
(2.6 \%)\end{array}$ & $\begin{array}{c}2 \\
(1.4 \%)\end{array}$ & - & & & & \\
\hline c. $10225 C>G$ & & & & & & & & $<0.001$ & 0.78 & 0.65 & 0.27 \\
\hline $\mathrm{GG}$ & $\begin{array}{c}51 \\
(11.5 \%)\end{array}$ & $\begin{array}{c}9 \\
(9.8 \%)\end{array}$ & $\begin{array}{c}60 \\
(11.2 \%)\end{array}$ & $\begin{array}{c}29 \\
(23.4 \%)\end{array}$ & $\begin{array}{c}20 \\
(21.3 \%)\end{array}$ & $\begin{array}{c}49 \\
(22.5 \%)\end{array}$ & $\begin{array}{c}126 \\
(28.7 \%)\end{array}$ & & & & \\
\hline GC & $\begin{array}{c}196 \\
(44.2 \%)\end{array}$ & $\begin{array}{c}40 \\
(43.5 \%)\end{array}$ & $\begin{array}{c}236 \\
(44.1 \%)\end{array}$ & $\begin{array}{c}69 \\
(55.6 \%)\end{array}$ & $\begin{array}{c}59 \\
(62.8 \%)\end{array}$ & $\begin{array}{c}128 \\
(58.7 \%)\end{array}$ & $\begin{array}{c}207 \\
(47.2 \%)\end{array}$ & & & & \\
\hline $\mathrm{CC}$ & $\begin{array}{c}196 \\
(44.2 \%)\end{array}$ & $\begin{array}{c}43 \\
(46.7 \%)\end{array}$ & $\begin{array}{c}239 \\
(44.7 \%)\end{array}$ & $\begin{array}{c}26 \\
(21 \%)\end{array}$ & $\begin{array}{c}15 \\
(15.9 \%)\end{array}$ & $\begin{array}{c}41 \\
(18.8 \%)\end{array}$ & $\begin{array}{c}106 \\
(24.1 \%)\end{array}$ & & & & \\
\hline
\end{tabular}

$\mathrm{EA}=$ European ancestry; $\mathrm{AfA}=$ African ancestry; DM2 = type 2 diabetes mellitus; Control = DM2-free blood donor volunteers. 
set of 207 DM2 subjects and the group of 439 non-diabetic individuals from quilombo remnants (age: $43.42 \pm 17.57$ years) in order to increase the power of the study.

In the total sample of DM2 patients ( $N=567)$, we confirmed the lack of association between this SNP and DM2 both in EA (DM2 group: $10225 \mathrm{G}=0.34$; control group: $10225 G=0.31 ; P=0.78)$ and $A f A(D M 2$ group: $10225 G=0.51$; control group: $10225 G=0.53 ; P=0.65$ ) individuals. Except for HDL cholesterol, clinical and anthropometric features in DM2 [total cholesterol (EA: $P=$ 0.31; AfA: $P=0.33$ ), LDL cholesterol (EA: $P=0.17$; AfA: $P$ $=0.11$ ), serum creatinine (EA: $P=0.49 ;$ AfA: $P=0.89)$, triglycerides ( $E A: P=0.53$; AfA: $P=0.49$ ), systolic blood pressure (EA: $P=0.43$; AfA: $P=0.48$ ), diastolic blood pressure $(E A: P=0.25$; AfA: $P=0.79)$, height $(E A: P=$ 0.73; AfA: $P=0.90)$, weight $(E A: P=0.83$; AfA: $P=0.58)$, $\mathrm{BMI}(\mathrm{EA}: \mathrm{P}=0.72$; AfA: $\mathrm{P}=0.86)$, waist circumference (EA: $P=0.22 ;$ AfA: $P=0.74), H b A 1 c(E A: P=0.42 ;$ AfA: $P=$ $0.60)$, and plasma glucose (EA: $P=0.09$; AfA: $P=0.74)$ ] were not associated with different genotypes of the SNP c. $10225 \mathrm{C}>\mathrm{G} / A D I P O R 1$. Thus, the previous correlation we found between allele 10225G and lower BMI was not confirmed after increasing sample size. We observed that HDL cholesterol was significantly higher in AfA heterozygotes $(\mathrm{GC}=53.75 \pm 17.26 \mathrm{mg} / \mathrm{dL})$ than in homozygotes $(\mathrm{CC}=44.75 \pm 10.93 \mathrm{mg} / \mathrm{dL} ; \mathrm{GG}=46.00 \pm 12.52 \mathrm{mg} / \mathrm{dL} ; P$ $=0.02$; of which, $\mathrm{P}=0.06$ between $\mathrm{GC}$ and $\mathrm{CC}$ genotypes, $P=0.11$ between $G C$ and $G G$ genotypes and $P=1.0$ between CC and GG genotypes, after performing the post hoc Bonferroni test). This association was not found with EA $(P=0.49)$.

In quilombo remnant individuals, the allele frequency of $10225 \mathrm{G}$ was 0.52 . Clinical and anthropometric features in these individuals were not associated with any genotype of the SNP C.10225C>G/ADIPOR1 [systolic blood pressure $(P=0.23)$, diastolic blood pressure $(P=0.42)$, height $(P=0.66)$, weight $(P=0.27)$, BMI $(P=0.52)$, waist circumference $(P=0.18)$, and plasma glucose level $(P=$ $0.17)]$.

Thus, the present study characterizes for the first time ADIPOR 1 SNPs c. $-8503 \mathrm{G}>\mathrm{A}$ and $\mathrm{c} .10225 \mathrm{C}>\mathrm{G}$ in groups of the Brazilian population, including quilombo remnants.

The low allele frequency of both SNPs in our EA sample $(-8503 A=0.27$ and $10225 G=0.32)$ was very similar to the frequency found in American Caucasoid, Finnish, German, French, UK, and HapMap Caucasian populations $(-8503 \mathrm{~A}=0.25-0.3$ and $10225 \mathrm{G}=0.31-0.33)$ $(4,6-9,17)$; but our SNP 10225G frequency was different from Old Order Amish $(-8503 \mathrm{~A}=0.27$ and $10225 \mathrm{G}=$
0.132) (3), probably because they represent an isolated population. This result thus suggests that the Caucasian population is relatively homogeneous worldwide for these SNPs.

Although quilombo remnants form a semi-isolated population (15), no significant difference in SNP c.10225C>G minor allele frequency was found compared to the Brazilian AfA groups. Minor allele frequency in our AfA sample $(-8503 A=0.16$ and $10225 G=0.52)$ was different from that in African-Americans $(-8503 A=0.36$ and $10225 G=0.42)$. Different origins of African-derived populations in the US and in Brazil or different proportions of admixture of the AfA population in Brazil could explain this. These data indicate the importance of analyzing EA and AfA separately in case-control studies, as we have already suggested (12). Moreover, the data suggest that these SNPs could represent valuable ancestry markers, which can be used to distinguish between chromosomal segments of subjects of AfA and EA.

We did not observe any association of ADIPOR1SNPS with DM2 in any of the groups studied here and with $\mathrm{HbA} 1 \mathrm{c}$ or BMI, which is consistent with several previous reports (3-9). Siitonen et al. (9) reported an association of ADIPOR1 SNPs and some metabolic traits according to gender. Our negative results cannot be explained by gender because the genotype distribution did not differ between male and female (data not shown).

The only positive significant association detected was in the DM2 AfA group, in which SNP c.10225C>G heterozygotes showed significantly higher HDL cholesterol levels than homozygotes. This cannot yet be explained at the functional level, but it is known that adiponectin levels correlate positively to HDL cholesterol levels and insulinstimulated glucose disposal $(18,19)$. However, the difference found between heterozygotes and homozygotes (8.33 $\mathrm{mg} / \mathrm{dL}$ ) was lower than the minimum detectable difference $(9.67 \mathrm{mg} / \mathrm{dL})$ with an acceptable power level $(P>0.8)$ in this sample size. Hence, validation of these data in other samples of African ancestry is necessary to exclude the possibility of false positive.

Our data show that ADIPOR1 gene variants do not represent major risk factors for DM2, increased BMI or any of the traits analyzed in European and African descendants, even though it should be noted that our sample size had statistical power to detect 1.5 times or greater difference between groups for both populations. On the other hand, these markers may be considered to be informative markers for admixture mapping. 


\section{References}

1. Kadowaki T, Yamauchi T. Adiponectin and adiponectin receptors. Endocr Rev 2005; 26: 439-451.

2. Yamauchi T, Kamon J, Ito Y, Tsuchida A, Yokomizo T, Kita $\mathrm{S}$, et al. Cloning of adiponectin receptors that mediate antidiabetic metabolic effects. Nature 2003; 423: 762-769.

3. Damcott CM, Ott SH, Pollin TI, Reinhart LJ, Wang J, O' Connell JR, et al. Genetic variation in adiponectin receptor 1 and adiponectin receptor 2 is associated with type 2 diabetes in the Old Order Amish. Diabetes 2005; 54: 2245-2250.

4. Wang $\mathrm{H}$, Zhang $\mathrm{H}$, Jia $\mathrm{Y}$, Zhang $\mathrm{Z}$, Craig $\mathrm{R}$, Wang $\mathrm{X}$, et al. Adiponectin receptor 1 gene (ADIPOR1) as a candidate for type 2 diabetes and insulin resistance. Diabetes 2004; 53 : 2132-2136.

5. Hara K, Horikoshi M, Kitazato H, Yamauchi T, Ito C, Noda $\mathrm{M}$, et al. Absence of an association between the polymorphisms in the genes encoding adiponectin receptors and type 2 diabetes. Diabetologia 2005; 48: 1307-1314.

6. Vaxillaire M, Dechaume A, Vasseur-Delannoy V, Lahmidi S, Vatin V, Lepretre F, et al. Genetic analysis of ADIPOR1 and ADIPOR2 candidate polymorphisms for type 2 diabetes in the Caucasian population. Diabetes 2006; 55: 856-861.

7. Collins SC, Luan J, Thompson AJ, Daly A, Semple RK, O'Rahilly S, et al. Adiponectin receptor genes: mutation screening in syndromes of insulin resistance and association studies for type 2 diabetes and metabolic traits in UK populations. Diabetologia 2007; 50: 555-562.

8. Stefan N, Machicao F, Staiger H, Machann J, Schick F, Tschritter $\mathrm{O}$, et al. Polymorphisms in the gene encoding adiponectin receptor 1 are associated with insulin resistance and high liver fat. Diabetologia 2005; 48: 2282-2291.

9. Siitonen N, Pulkkinen L, Mager U, Lindstrom J, Eriksson JG, Valle TT, et al. Association of sequence variations in the gene encoding adiponectin receptor 1 (ADIPOR1) with body size and insulin levels. The Finnish Diabetes Prevention Study. Diabetologia 2006; 49: 1795-1805.

10. Canani LH, Capp C, Ng DP, Choo SG, Maia AL, Nabinger
$\mathrm{GB}$, et al. The fatty acid-binding protein-2 A54T polymorphism is associated with renal disease in patients with type 2 diabetes. Diabetes 2005; 54: 3326-3330.

11. Errera FI, Silva ME, Yeh E, Maranduba CM, Folco B, Takahashi W, et al. Effect of polymorphisms of the MTHFR and APOE genes on susceptibility to diabetes and severity of diabetic retinopathy in Brazilian patients. Braz J Med Biol Res 2006; 39: 883-888.

12. Errera FI, Canani LH, Silva ME, Yeh E, Takahashi W, Santos KG, et al. Functional vascular endothelial growth factor $-634 G>C$ SNP is associated with proliferative diabetic retinopathy: a case-control study in a Brazilian population of European ancestry. Diabetes Care 2007; 30: 275-279.

13. American Diabetes Association. Diagnosis and classification of diabetes mellitus. Diabetes Care 2005; 28 (Suppl 1): S37-S42.

14. Department of Nutrition for Health and Development (NHD) of the World Health Organization. BMI classification. http:// www.who.int/bmi/index.jsp?introPage = intro_3.html. Accessed February 15, 2006.

15. Cotrim NH, Auricchio MT, Vicente JP, Otto PA, MingroniNetto RC. Polymorphic Alu insertions in six Brazilian African-derived populations. Am J Hum Biol 2004; 16: 264-277.

16. Dupont WD, Plummer WD. PS power and sample size program available for free on the Internet. Controlled Clin Trials 1997; 18: 274.

17. The International HapMap Project. Nature 2003; 426: 789796.

18. Weyer C, Funahashi T, Tanaka S, Hotta K, Matsuzawa Y, Pratley RE, et al. Hypoadiponectinemia in obesity and type 2 diabetes: close association with insulin resistance and hyperinsulinemia. J Clin Endocrinol Metab 2001; 86: 19301935.

19. Matsubara M, Maruoka S, Katayose S. Decreased plasma adiponectin concentrations in women with dyslipidemia. $J$ Clin Endocrinol Metab 2002; 87: 2764-2769. 